\title{
Effects of Low Ag Doping on Physical and Optical Waveguide Properties of Highly Oriented Sol-Gel ZnO Thin Films
}

\author{
Mohamed Dehimi, ${ }^{1}$ Tahar Touam, ${ }^{1}$ Azeddine Chelouche, ${ }^{2}$ \\ Fares Boudjouan, ${ }^{2}$ Djamel Djouadi, ${ }^{2}$ Jeanne Solard, ${ }^{3}$ Alexis Fischer, ${ }^{3}$ \\ Azzedine Boudrioua, ${ }^{3}$ and Abdellaziz Doghmane ${ }^{1}$ \\ ${ }^{1}$ Semiconductors Laboratory, University of Badji Mokhtar-Annaba, BP 12, Annaba 23000, Algeria \\ ${ }^{2}$ Environmental Engineering Laboratory, University of Béjaïa, Béjaïa 06000, Algeria \\ ${ }^{3}$ Laser Physics Laboratory CNRS UMR 7538, University of Paris 13, Sorbonne Paris City, 93430 Villetaneuse, France
}

Correspondence should be addressed to Tahar Touam; touamt@gmail.com

Received 19 April 2015; Revised 24 June 2015; Accepted 29 June 2015

Academic Editor: David Huber

Copyright (C) 2015 Mohamed Dehimi et al. This is an open access article distributed under the Creative Commons Attribution License, which permits unrestricted use, distribution, and reproduction in any medium, provided the original work is properly cited.

A sol-gel dip-coating process was used to deposit almost stress-free highly c-axis oriented zinc oxide ( $\mathrm{ZnO}$ ) thin films onto glass substrates. The effects of low silver doping concentration $(\mathrm{Ag} / \mathrm{Zn}<1 \%)$ on the structural, morphological, optical, and waveguide properties of such films were investigated by X-ray diffraction (XRD), scanning electron microscopy (SEM), atomic force microscopy, UV-Visible spectrophotometry, and M-lines spectroscopy (MLS). XRD analysis revealed that all the films were in single phase and had a hexagonal wurtzite structure. The grain size values were calculated and found to be about $24-29 \mathrm{~nm}$. SEM micrographs and AFM images have shown that film morphology and surface roughness were influenced by Ag doping concentration. According to UV-Vis. measurements all the films were highly transparent with average visible transmission values ranging from $80 \%$ to $86 \%$. It was found that the Ag contents lead to widening of the band gap. MLS measurements at $632.8 \mathrm{~nm}$ wavelength put into evidence that all thin film planar waveguides demonstrate a well-guided fundamental mode for both transverse electric and transverse magnetic polarized light. Moreover, the refractive index of $\mathrm{ZnO}$ thin films was found to increase by $\mathrm{Ag}$ doping levels.

\section{Introduction}

In recent years, zinc oxide $(\mathrm{ZnO})$ has emerged as a promising material for a large number of fundamental and applied fields due to its numerous interesting characteristics including direct wide band gap $(3.37 \mathrm{eV})$ semiconductor with a large excitation binding energy $(60 \mathrm{meV})$, material stability, high refractive indices, high values for second- and third-order nonlinear optical susceptibility tensors, and high internal quantum well efficiency [1-4]. These advantages place $\mathrm{ZnO}$ as an ideal candidate for several potential applications ranging from transparent conducting coatings [5] to flat panel displays (FPD) [6], solar cell windows [7], and photonic [8] and surface acoustic wave (SAW) devices [9], as well as for the realization of new generation of optoelectronic devices such as polariton lasers at room temperature [10].

As a result of recent progress in materials science technology, undoped and doped $\mathrm{ZnO}$ thin films have been prepared by a variety of techniques such as spray pyrolysis [11], e-beam evaporation [12], pulsed laser deposition (PLD) [13], chemical vapor deposition (CVD) [14], direct current (DC) and radio frequency (RF) sputtering $[15,16]$, and sol-gel methods [17, 18]. Among these approaches, the sol-gel process has attracted large attention due to its simplicity, low cost, easy adjusting composition and dopants, homogeneity on the molecular level, and lower crystallization temperature.

$\mathrm{ZnO}$ doping with selective elements is the most effective alternative to improve its structural, electrical, magnetic, 
and optical properties without any change in the crystalline structure $[19,20]$. Among these elements, Ag has been one of the most extensively used dopants whose effects on $\mathrm{ZnO}$ thin film properties have been widely investigated $[17,18,21-$ 31]. It was reported that the properties of $\mathrm{Ag}$ doped $\mathrm{ZnO}$ thin films are strongly influenced by deposition techniques, fabrication parameters, annealing treatments, and Ag doping concentrations. Despite this large number of experimental reports of $\mathrm{Ag}$ doped $\mathrm{ZnO}$ thin films, no consensus has been reached; the published data are mostly inconsistent and controversial [17, 18, 21-24, 27-30]. Furthermore, only moderate or high Ag doping levels where studied. In this context, we complete and enrich our understanding of $\mathrm{Ag}$ doped $\mathrm{ZnO}$ films via the investigation of the influence of low $\mathrm{Ag}$ doping concentrations ( $\mathrm{Ag}<1$ at.\%) on $\mathrm{ZnO}$ thin films properties. Moreover, to the best of our knowledge, a systematic study by the MLS technique [32] on the waveguide propagating modes and the corresponding refractive indices of sol-gel Ag doped $\mathrm{ZnO}$ thin films on glass substrates has not yet been reported.

In the present study, $\mathrm{ZnO}$ thin films have been deposited onto glass substrates using a sol-gel dip-coating process. A systematic investigation was conducted to reveal the effects of low silver doping concentration on the structural, morphological, optical, and waveguide properties by using various characterization techniques.

\section{Experimental Details}

Undoped and $\mathrm{Ag}$ doped $\mathrm{ZnO}$ thin films were prepared by the sol-gel process. As a starting material, zinc acetate dihydrate $\left(\mathrm{Zn}\left(\mathrm{CH}_{3} \mathrm{COO}\right)_{2} 2 \mathrm{H}_{2} \mathrm{O}\right)$ (Sigma-Aldrich) was dissolved in a mixture of absolute ethanol (EtOH, 100\%, BioChem) and monoethanolamine (MEA) (Sigma-Aldrich) yielding to a precursor concentration of $0.75 \mathrm{~mol} \mathrm{~L}^{-1}$. The MEA to zinc acetate molar ratio was set to 1 . For doped films, silver nitrate $\left(\mathrm{AgNO}_{3}\right)$ was added to the mixture with an atomic percentage fixed at $0.3,0.5,0.7$, and 0.9 at. $\% \mathrm{Ag}$, respectively. The resulting sols were magnetically stirred at $60^{\circ} \mathrm{C}$ for 1 hour and then aged at room temperature for two days to get clear and transparent homogeneous solutions. Prior to film deposition, commercial glass substrates (Esco Optics) were ultrasonically cleaned by using deionized water, ethanol, and acetone for $15 \mathrm{~min}$, respectively. Then, the substrates were dried in an oven at $100^{\circ} \mathrm{C}$ for $30 \mathrm{~min}$. The substrates were dipped in the prepared sols and then withdrawn at a constant dip-coating speed of $15 \mathrm{~mm} / \mathrm{min}$ (KSV 67 NIMA dip coater). After each deposition, all samples were preheated at $200^{\circ} \mathrm{C}$ for $10 \mathrm{~min}$ to remove the solvent and organic residuals. This process cycle was repeated 6 times to increase the film thickness. These samples were annealed in an air atmosphere furnace for one hour at $500^{\circ} \mathrm{C}$ and then cooled to room temperature before taken to the material characterization stage.

The crystalline structure of $\mathrm{ZnO}$ thin films thus prepared was characterized via the XRD technique with a PanAlytical diffractometer. The latter was operated at $40 \mathrm{kV}$ and $30 \mathrm{~mA}$ using $\mathrm{Cu} \mathrm{K} \alpha$ radiation at a grazing incidence $\left(\omega=0.54^{\circ}\right)$.
The microstructures associated with the sol-gel derived $\mathrm{ZnO}$ films were analyzed by using the technique of SEM by a Raith PIONEER System. Surface morphology of thin films was examined in contact mode by Nanosurf easyScan 2 operated at room temperature and equipped with a $10 \mu \mathrm{m} \times 10 \mu \mathrm{m}$ high resolution scanner with vertical range of $2 \mu \mathrm{m}$. AFM images have been recorded with a resolution of $512 \times 512$ pixels. The optical transmittance spectra were collected at room temperature by a Safas UVmc ${ }^{2}$ UV-Vis. spectrophotometer and the optical bandgap energy data was then derived from the transmission spectra. Optical waveguiding characterizations of the thin films were carried out by MLS using a Metricon 2010/M Prism Coupler apparatus. The film thickness of the all samples was measured by using a Veeco Dektak 150 Surface Profiler.

\section{Results and Discussion}

The crystalline structure and orientation of all the prepared thin films were studied using XRD with their patterns recorded in a $\theta-2 \theta$ mode from 25 up to $70^{\circ}$ at a resolution of $0.017^{\circ}$ per step size. Displayed in Figure 1(a) are the typical XRD spectra of samples associated with the conditions of undoped and $\mathrm{Ag}$ doped $\mathrm{ZnO}$ thin films at different concentrations. The angular peak position of the XRD signals corresponding to bulk $\mathrm{ZnO}$ is indicated by a dotted line located at $2 \theta=34.43^{\circ}$ (Figure 1(b)) according to the XRD assignment by the American Society for Testing and Materials ASTM: 36-1451. It can clearly be seen from the XRD data that there are no extra peaks due to silver or any zinc silver phase, indicating that the synthesized films are in a single phase of hexagonal wurtzite structure. Moreover, the strong peak along [002] direction confirms that the $\mathrm{ZnO}$ is well crystallized and the crystallites are highly oriented with their $c$-axes normal to the deposition substrate plane. From Figures 1(a) and 1(b), it is can be seen that increasing the silver concentration does not affect the preferential growth of the films. In addition, the angular peak position value of (002) planes did not shift and almost perfectly matched the angular value of ideal $\mathrm{ZnO}$ bulk peak demonstrating that the lattice parameter $c$ almost did not change and was not influenced by the Ag doping levels in the starting solution.

The residual stress $(\sigma)$ of the thin films can be determined from a biaxial strain model analysis [33]. Accordingly, the lattice parameters and elastic stiffness constants of the single crystal $\mathrm{ZnO}$ are related in the following formula:

$$
\sigma=\frac{2 C_{13}^{2}-C_{33}\left(C_{11}+C_{12}\right)}{2 C_{13}} \times \frac{\left(c-c_{0}\right)}{c_{0}},
$$

where $c_{0}=5.206 \AA$ is the unstrained lattice constant of $\mathrm{ZnO}$ along the $c$-axis and $c$ is the lattice parameter of strained $\mathrm{ZnO}$ films calculated from the XRD data by means of the Bragg equation. $C_{13}=104,2 \mathrm{GPa}, C_{33}=213,8 \mathrm{GPa}, C_{11}=208,8 \mathrm{GPa}$, and $C_{12}=119,7 \mathrm{GPa}$ are the elastic stiffness constant values of single crystal $\mathrm{ZnO}$ [34].

In Figure 2 we illustrate the data of $c$ lattice constant and residual stress converted from the above analysis for the 


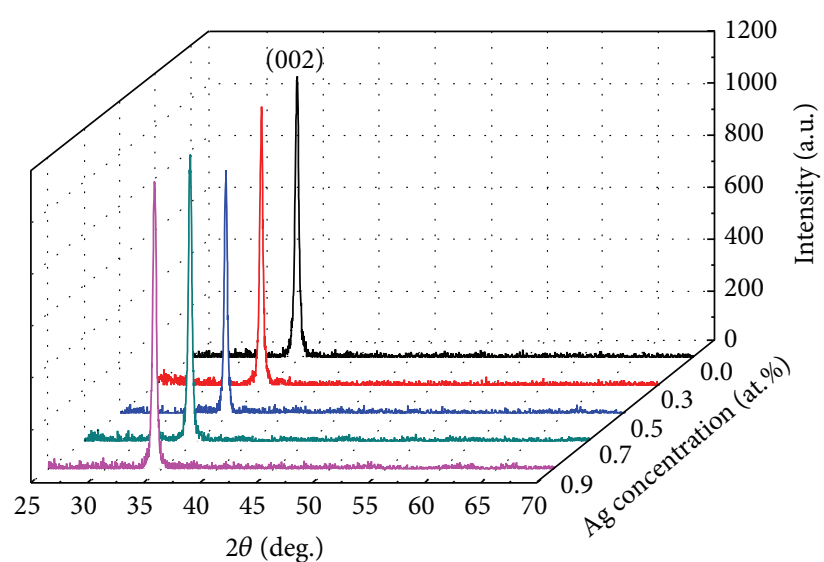

(a)

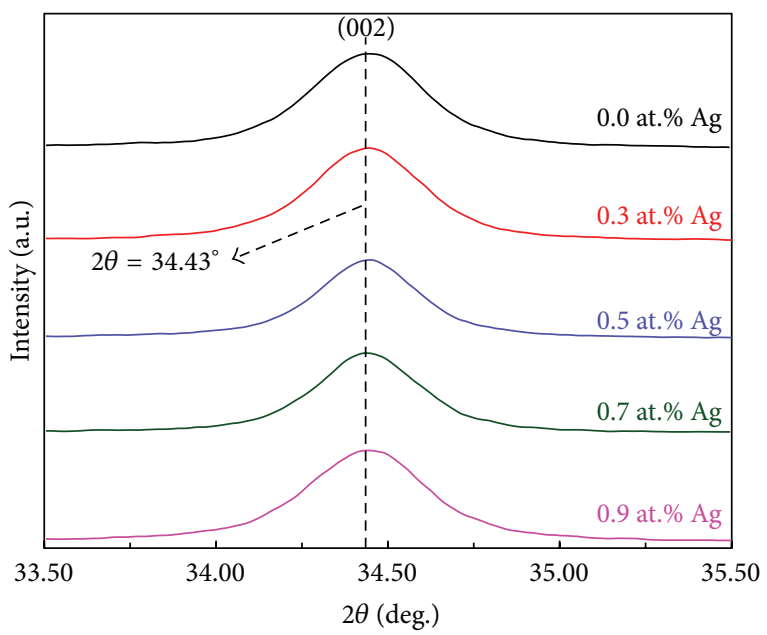

(b)

FIgure 1: (a) XRD patterns of undoped and Ag doped $\mathrm{ZnO}$ thin films and (b) magnified region of (002) peak.

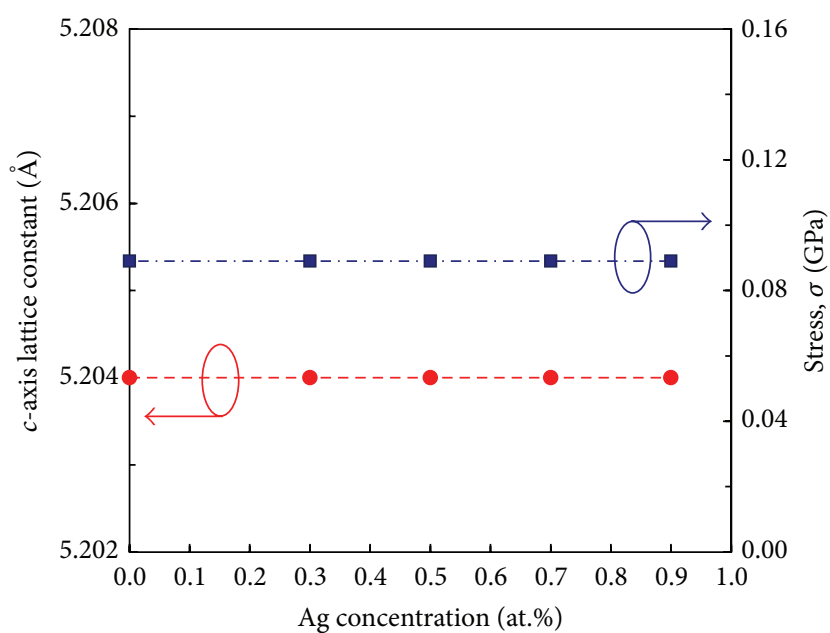

FIGURE 2: $c$-axis lattice constant and residual stress of undoped and Ag doped $\mathrm{ZnO}$ thin films.

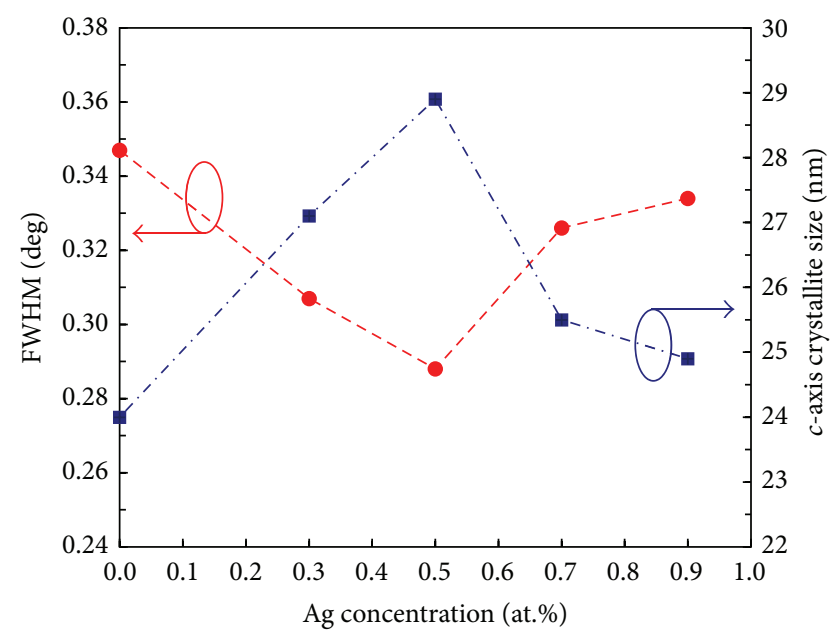

FIgURE 3: FWHM and $c$-axis lattice crystallite size of undoped and Ag doped $\mathrm{ZnO}$ thin films.

undoped and $\mathrm{Ag}$ doped $\mathrm{ZnO}$ thin films. From Figure 2 it was noted that with increase of Ag doping concentration, the lattice parameter value was found to remain unchanged and equal to that of undoped $\mathrm{ZnO}$. These observations show that undoped and $\mathrm{Ag}$ doped $\mathrm{ZnO}$ thin films deposited by our developed sol-gel process were virtually stress-free and highly $c$-axis oriented.

To compare the microstructure features of the $\mathrm{ZnO}$ thin films subject to different Ag doping concentrations, the fullwidth at half-maximum (FWHM) corresponding to the XRD (002) peaks was measured and depicted in Figure 3. The average crystallite sizes, $D$, of these $c$-axis oriented thin films were estimated from the FWHM of (002) diffraction peak according to the well-known Scherer's formula [35]:

$$
D=\frac{0.9 \lambda}{\beta \cos \theta},
$$

where $\lambda=0.154056 \mathrm{~nm}$ is the $\mathrm{X}$-ray wavelength and $\beta$ is the FWHM of the XRD signal with peak position at $\theta$ in radian.

Figure 3 illustrates the calculated average crystallite size values for undoped and $\mathrm{Ag}$ doped samples at different concentrations. The mean crystallite size is seen to be strongly dependent on the amount of Ag doping. As can be found in Figure 2, the crystallite size is increased from $27.1 \mathrm{~nm}(\mathrm{Ag}=$ 0.3 at.\%) to a maximum value of $28.9 \mathrm{~nm}$ for the $\mathrm{ZnO}$ thin film doped at 0.5 at.\%. However, opposite tendency is observed for higher Ag doping levels ( $>0.5$ at $\%)$; that is, the crystallite size is found to decrease with $\mathrm{Ag}$ concentration from $25.5 \mathrm{~nm}(\mathrm{Ag}=0.7$ at.\%) to $24.9 \mathrm{~nm}(\mathrm{Ag}=0.9$ at.\%). Such behavior of the crystallite size may be explained as follows: for $\mathrm{Ag}$ concentration less than or equal to $0.5 \mathrm{at} . \%$, the $\mathrm{Ag}^{+}$is probable to act as an amphoteric dopant [36] and can occupy both the lattice and interstitial site. However, due to the difference of ionic charge and radius between $\mathrm{Zn}^{2+}$ ion $(0.088 \mathrm{~nm})$ and $\mathrm{Ag}^{+}$ion $(0.129 \mathrm{~nm})$, the segregation of $\mathrm{Ag}$ at the vicinity of the grain boundary of $\mathrm{ZnO}$ is preferred which probably favors the preferential growth of larger sized crystallites associated with a slight decrease in the maximum intensities of 
the (002) diffraction peak. Whereas, for Ag doping amounts higher than 0.5 at\%, since the solubility of $\mathrm{Ag}$ in $\mathrm{ZnO}$ is low, $\mathrm{Ag}$ atoms are incorporated in the grain boundaries and/or into the film surface leading to a reduction in the crystal grain size [37], similar trends have been observed in $\mathrm{ZnO}$ using Ag and other dopants $[36,37]$. The obtained results indicate that the addition of $\mathrm{Ag}$ may control the crystallite size of $\mathrm{ZnO}$ as observed for other transition metals such as $\mathrm{Co}$ and $\mathrm{Cr}$ $[38,39]$.

Undoped and $\mathrm{Ag}$ doped $\mathrm{ZnO}$ thin films were analyzed by SEM and AFM techniques in order to study their surface morphology and roughness. Prior to SEM imaging, the samples were coated with a $20-30 \mathrm{~nm}$ thick conducting layer of silver to prevent charge build-up. Figure 4 illustrates highmagnification SEM micrographs of the abovementioned samples. All the films showed a uniformly distributedlike spherical shaped grains and compactly packed grains distributed over the film surface. It is clear from these micrographs that the surface morphology of the $\mathrm{ZnO}$ films seems to be influenced by the Ag doping. The undoped $\mathrm{ZnO}$ thin film exhibits a smooth surface consisting of small spherical grain size particles. Whereas the surface morphology of the $\mathrm{Ag}$ doped $\mathrm{ZnO}$ thin films revealed different morphologies of the surface grains, which depend on Ag concentration, the average particle sizes increased with increasing percentage of $\mathrm{Ag}$ up to 0.5 at.\%. Beyond this, the particle size exhibits reverse behavior and starts decreasing with increasing Ag doping levels. This trend in the average particle sizes observed by SEM is in good agreement with that of crystallite sizes obtained from XRD data analysis.

Surface morphology of the thin films in terms of root mean squared roughness $\left(R_{\text {rms }}\right)$ was explored from the AFM collected images using the Gwyddion analysis software [40]. The $R_{\text {rms }}$ not only describes the light scattering but also gives an idea about the quality of the surface under investigation. Figures 5(a), 5(b), 5(c), 5(d), and 5(e) depict twodimensional (2D) and three-dimensional (3D) AFM images of the undoped and $\mathrm{Ag}$ doped $\mathrm{ZnO}$ thin films with different concentrations scanned over a surface area of $1 \times 1 \mu \mathrm{m}^{2}$. The films exhibit different surface roughness which seems to be dependent on the Ag doping. From the data analyses, one can infer $R_{\text {rms }}$ values of $2.40,3.72,4.05,2.89$, and $2.27 \mathrm{~nm}$ for undoped and 0.3, 0.5, 0.7, and 0.9 at.\% Ag-doped $\mathrm{ZnO}$ thin films, respectively. It can be seen that the undoped $\mathrm{ZnO}$ thin film exhibits low surface roughness. However, increasing Ag doping levels leads to an increase in $R_{\text {rms }}$ to reach a maximum value of $4.05 \mathrm{~nm}$ at 0.5 at.\% Ag contents; it then gradually decreases down to a minimum value of $2.27 \mathrm{~nm}$ at 0.9 at.\% Ag. According to this result, the enhancement in the surface roughness with the Ag content may be attributed to the decrease of $\mathrm{ZnO}$ grain sizes as revealed by SEM micrographs. Furthermore, the Ag doping may reduce the scattering at the film surface as reported by previous works $[21,36]$. Therefore, using Ag doped $\mathrm{ZnO}$ may improve the optical quality and waveguiding properties of the films, which are directly dependent on the roughness. Once again, the $R_{\text {rms }}$ values exhibit a similar tendency to that of crystallite and grain sizes observed from XRD and SEM analysis.
Figure 6(a) shows the optical transmittance spectra of undoped and $\mathrm{Ag}$ doped $\mathrm{ZnO}$ thin films at different concentrations measured with respect to air in the $300-1000 \mathrm{~nm}$ range. It can clearly be seen that the films are highly transparent in the visible region with an average optical transmittance ranging from $80 \%$ to $86 \%$. A slight decrease in average transmittance from $81.3 \%$ to $80 \%$ was observed for undoped and $\mathrm{Ag}$ doped $\mathrm{ZnO}$ films at 0.5 at.\%, respectively. However, for doping amounts higher than 0.5 at.\%, the films have shown better transparency with a maximum average transmittance value of about $86 \%$ obtained at 0.9 at. $\%$ Ag concentration. These results may be attributed to the surface roughness trends revealed by AFM analysis, as it was put into evidence that 0.5 at.\% doped films showed a maximum $R_{\text {rms }}$ value whereas a minimum value was obtained for films with 0.9 at. $\%$ concentration.

The direct bandgap energies $\left(E_{g}\right)$ of all the samples were determined by using a technique based on the derivative of the transmittance $(T)$ with respect to energy $(E), \mathrm{d} T / \mathrm{d} E$, taking into account that $\mathrm{ZnO}$ is a direct band gap semiconductor. This accurate method has been used by several authors [41]. According to the measured transmission spectra, the $\mathrm{d} T / \mathrm{d} E$ curves of undoped and $\mathrm{Ag}$ doped $\mathrm{ZnO}$ thin films at different concentrations are illustrated in Figure 6(b). Our analysis indicates that the $E_{g}$ of undoped $\mathrm{ZnO}$ film was found to be $3.229 \mathrm{eV}$ which is in very good agreement with literature [42]. Whereas the bandgap of Ag doped films increases initially and then is saturated at about $3.246 \mathrm{eV}$ for all Ag doping concentrations, this widening of the optical band gap suggests that the $\mathrm{Ag}^{+}$was not substituted into the $\mathrm{Zn}^{2+}$ [43] and typically can be explained in terms of Burstein-Moss shift $[44,45]$.

Optical properties of Ag doped $\mathrm{ZnO}$ films related to photonic device applications such as the waveguide propagating modes and refractive indices were further investigated by a Metricon 2010/M Prism Coupler apparatus equipped with a He-Ne laser beam operating at a $632.8 \mathrm{~nm}$ wavelength. This apparatus uses the MLS technique based on the prism coupling method [46]. Details of this technique can be found elsewhere [32].

Figures 7(a) and 7(b) display typical ordinary (TE) and typical extraordinary (TM) guided mode spectra of the undoped and $\mathrm{Ag}$ doped $\mathrm{ZnO}$ thin films at different concentrations. Our observations suggest that these film planar waveguides support only the fundamental TE and TM polarized modes. Moreover, from the FWHM of the mode spectra one can further expect that the $\mathrm{ZnO}$ thin film planar waveguides doped at 0.7 and 0.9 at.\% Ag concentrations would exhibit better light confinement and lower optical losses compared to other ones. The latter were reported in our previous study suggesting that guided mode spectra with smaller FWHM possess lower optical losses.

The thickness of all the films was measured by mechanical surface profiling and found to be about 199.6, 186.4, 231.5, 181.5, and $208.7 \mathrm{~nm}$ for $\mathrm{Ag}$ doped $\mathrm{ZnO}$ films at 0, 0.3, 0.5, 0.7 , and 0.9 at. $\%$ concentrations, respectively. These obtained thickness values and the measured effective refractive indices of the waveguide modes are used through the theoretical 

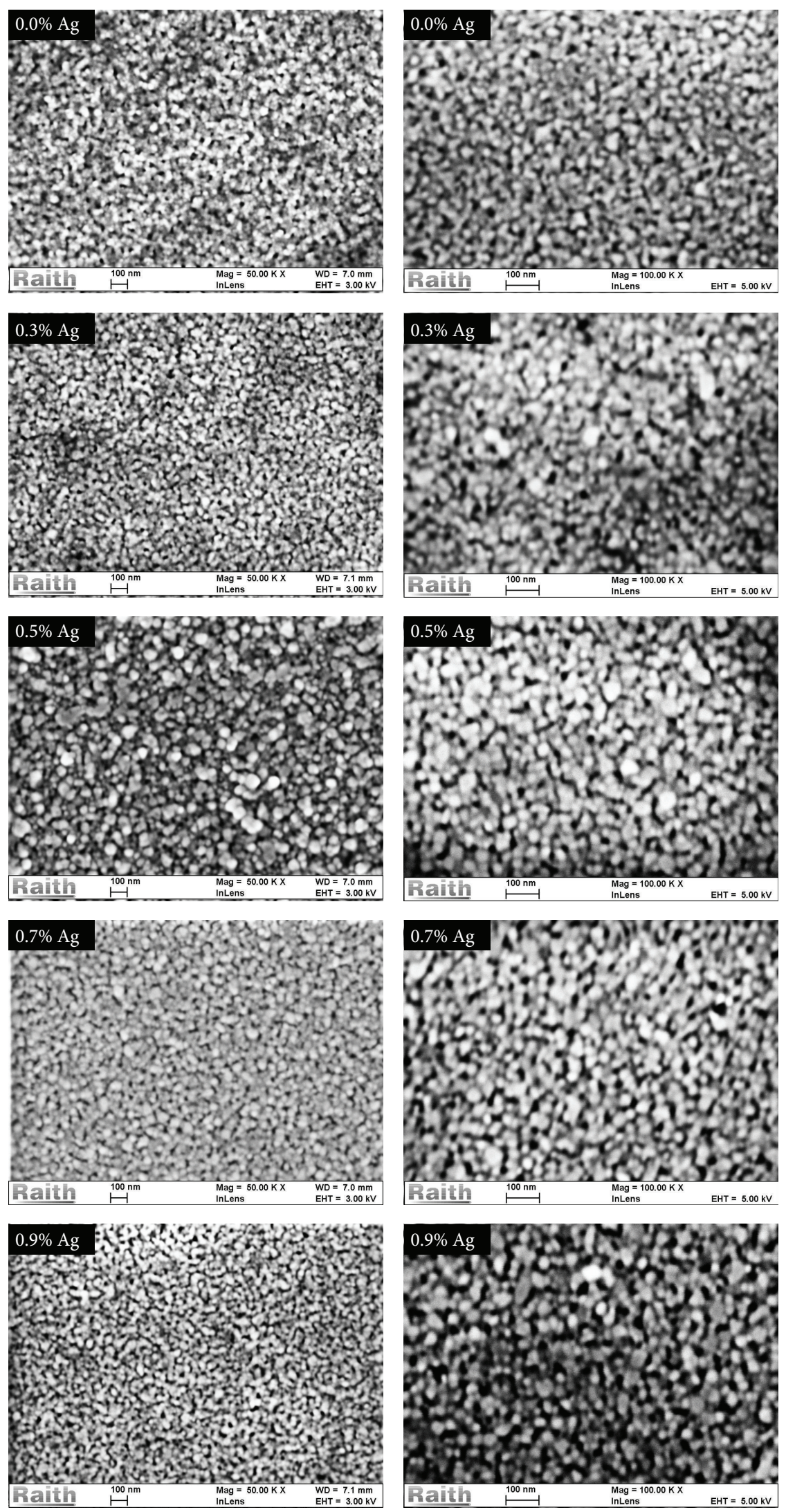

FIGURE 4: SEM micrographs of undoped and Ag doped ZnO thin films, $\times 50,000$ magnification (on the left side) and $\times 100,000$ magnification (on the right side). 

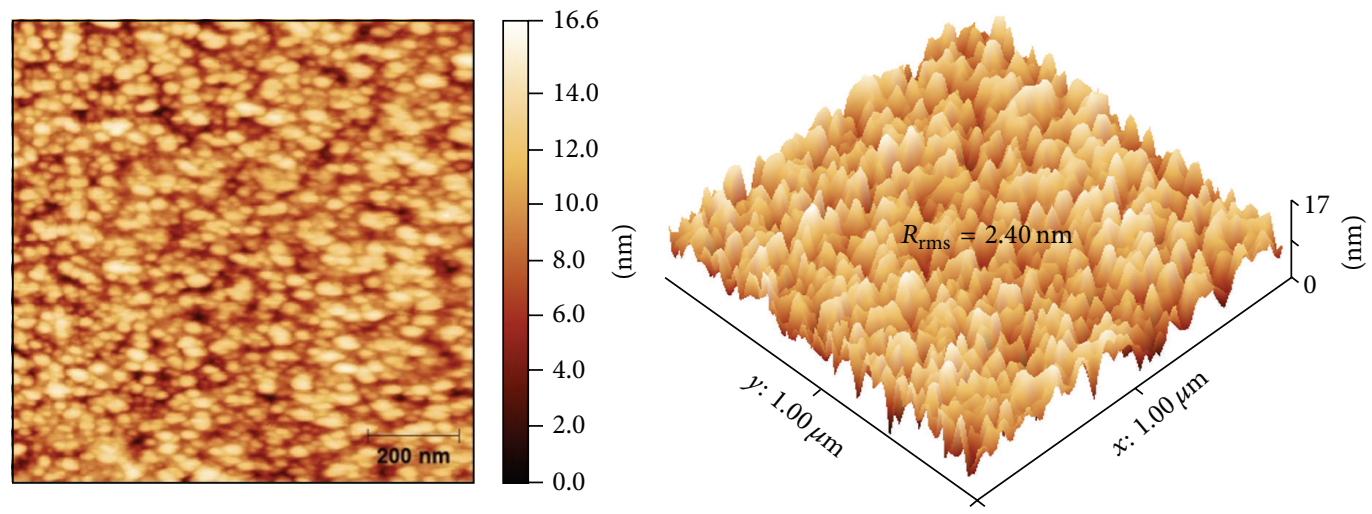

(a)
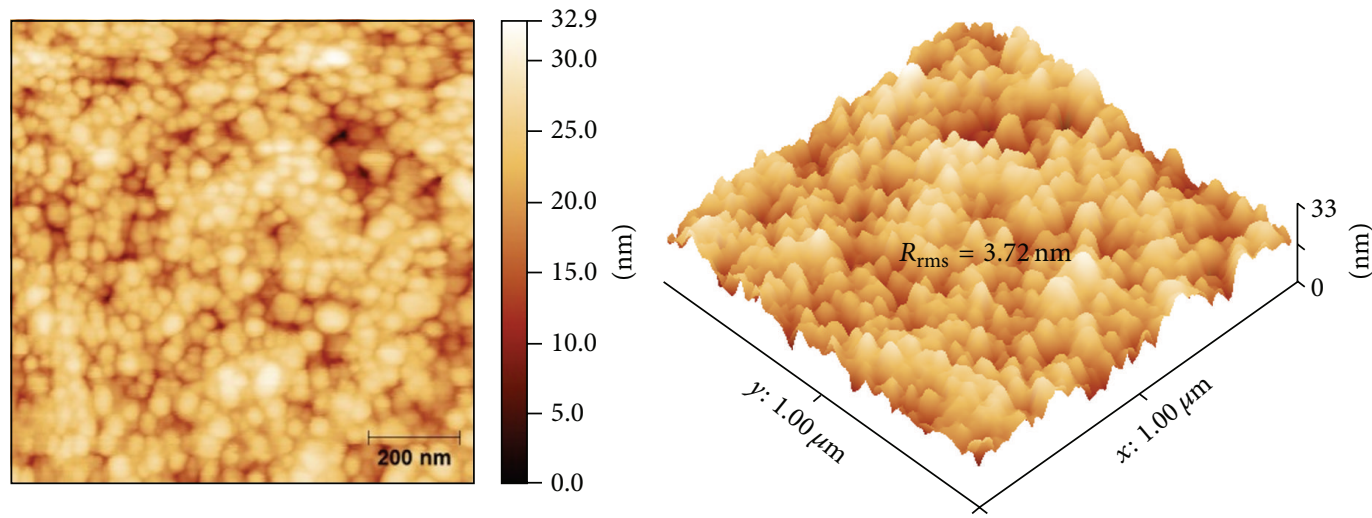

(b)
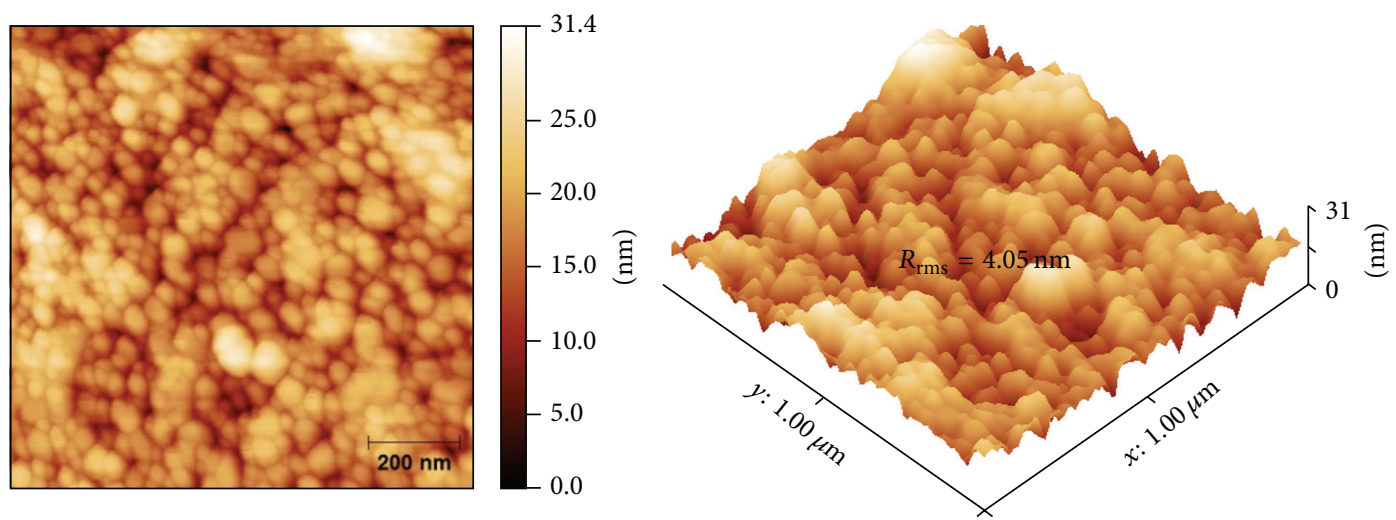

(c)
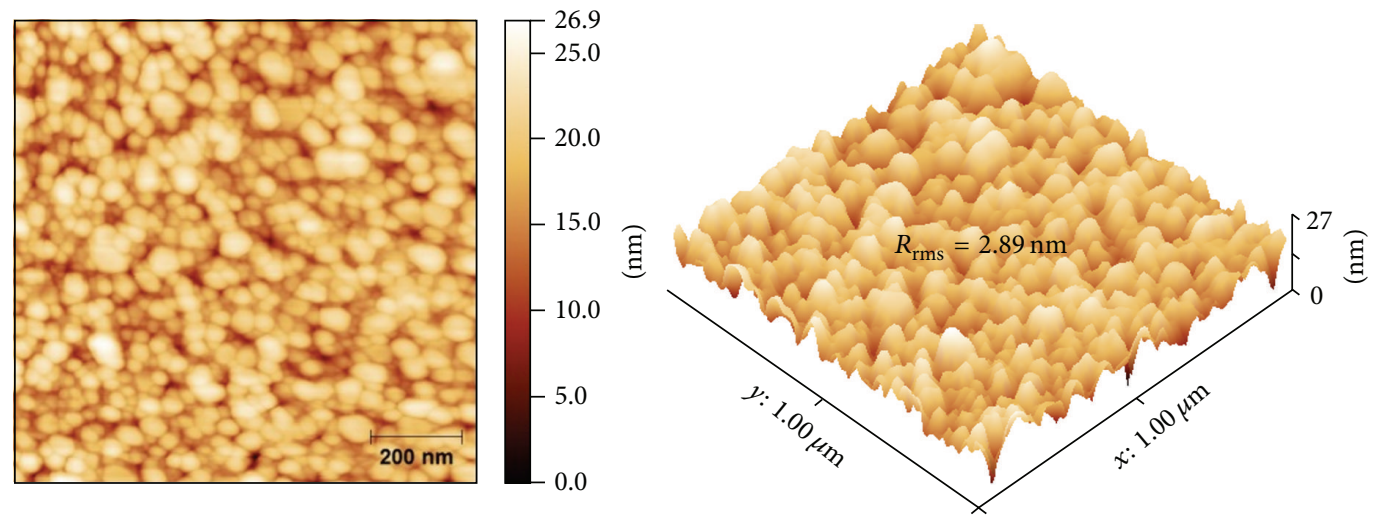

(d)

Figure 5: Continued. 

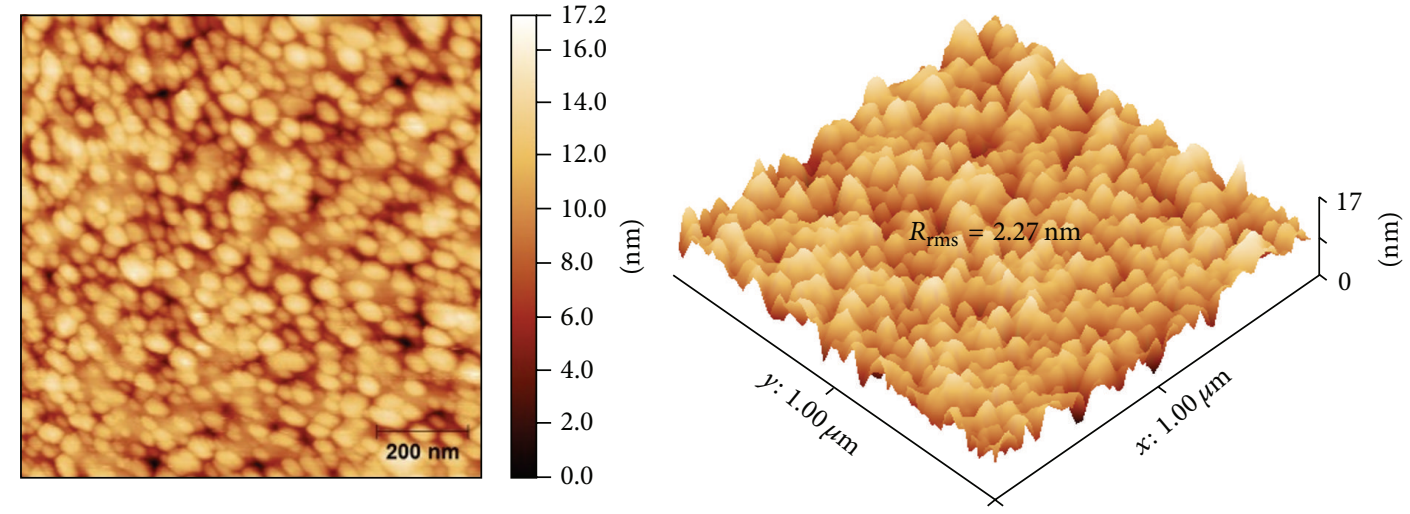

(e)

Figure 5: 2D and 3D AFM images of $\mathrm{Ag}$ doped $\mathrm{ZnO}$ thin films: (a) 0.0 at.\% $\mathrm{Ag}$, (b) 0.3 at.\% $\mathrm{Ag}$, (c) 0.5 at.\% $\mathrm{Ag}$, (d) 0.7 at.\% $\mathrm{Ag}$, and (e) 0.9 at. $\%$ Ag.

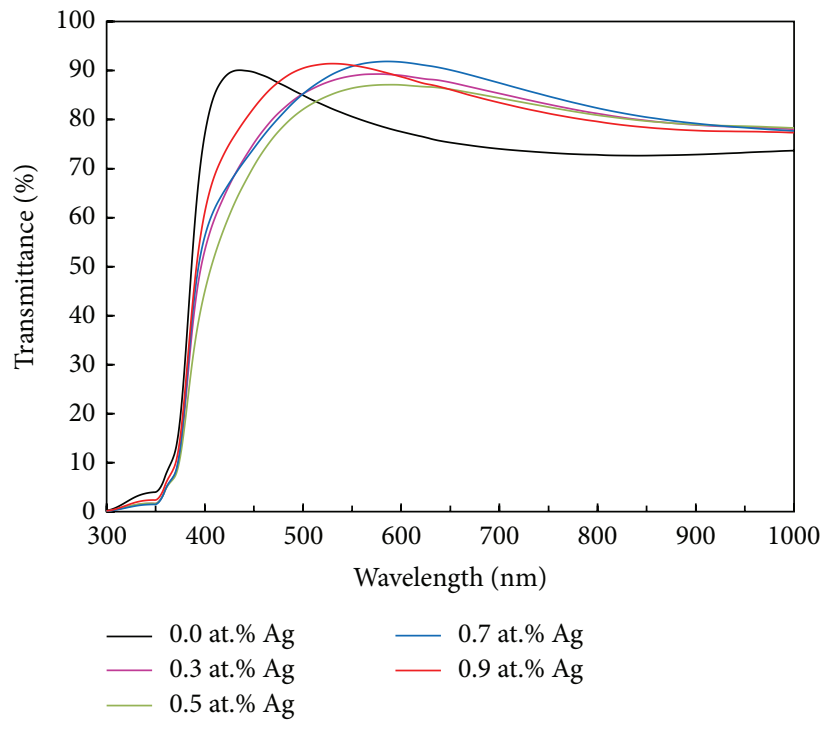

(a)

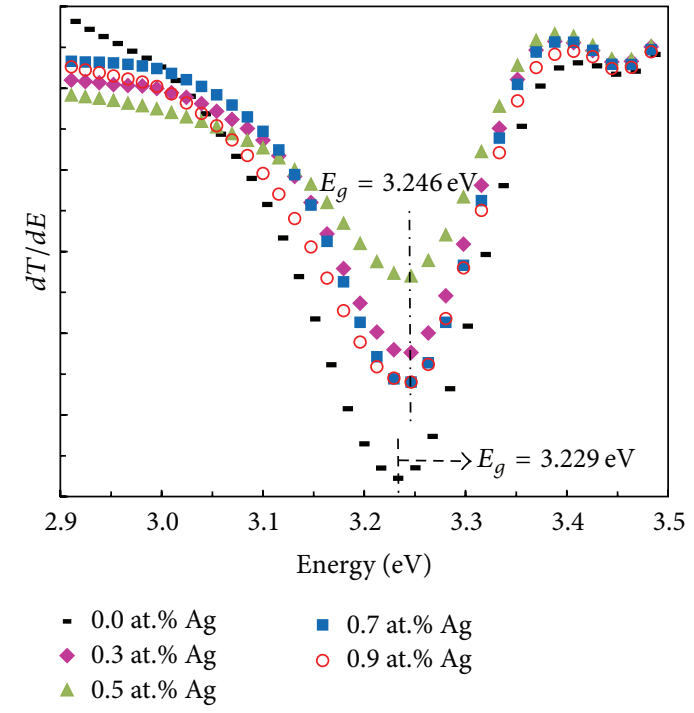

(b)

Figure 6: (a) UV-Vis. transmittance spectra of undoped and Ag doped $\mathrm{ZnO}$ thin films and (b) dT/dE plots of undoped and Ag doped $\mathrm{ZnO}$ thin films.

approach of MLS based on a step-index profile model for the refractive index calculations [46]. The obtained data are shown in Figure 8; they exhibit the correlation between the extracted value of the ordinary $\left(n_{o}\right)$ and the extraordinary $\left(n_{e}\right)$ refractive indexes with respect to $\mathrm{Ag}$ doping percentages. As can be seen from Figure 8, the extraordinary index of refraction is greater than the ordinary index which is consistent with the positive uniaxial anisotropy of $\mathrm{ZnO}$ material characterized by $n_{e}>n_{o}$ [47]. Furthermore, it is found that both $n_{o}$ and $n_{e}$ increase with Ag doping levels. These results are in agreement with previous works of García-Alamo et al. [48] who investigated the effects of moderate Ag doping concentration on refractive index of $\mathrm{ZnO}$ thin films and reported similar trend.
Based on all the above-mentioned results, it can be concluded that $\mathrm{ZnO}$ thin films doped with Ag concentrations as low as 0.7 and 0.9 at.\% revealed interesting characteristics of low surface roughness, high transparency, and enhanced waveguide properties suitable for photonic device applications.

\section{Conclusion}

Undoped and $\mathrm{Ag}$ doped $\mathrm{ZnO}$ thin films were successfully deposited onto glass substrates by the sol-gel dip-coating process. The effects of low silver doping concentration $(\mathrm{Ag}<$ 1 at.\%) on the structural, morphological, optical, and waveguide properties were investigated. XRD measurement 


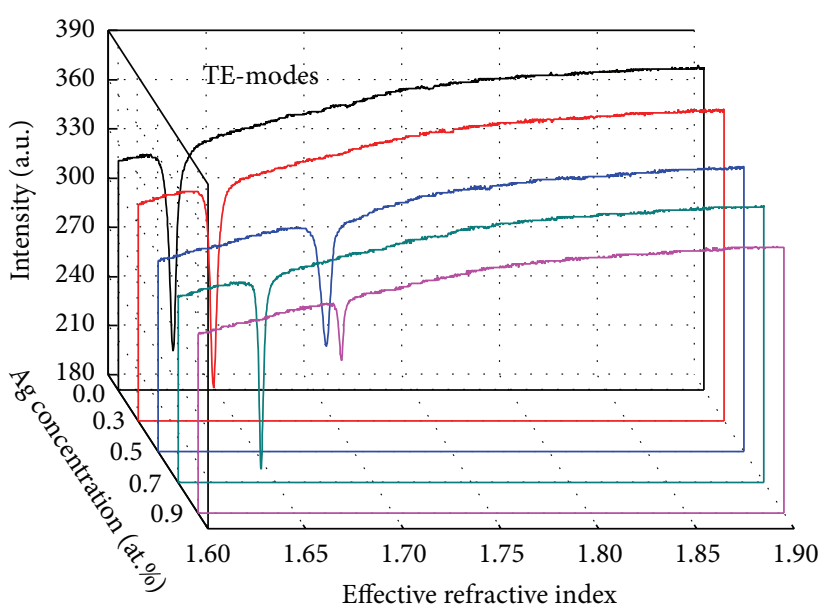

(a)

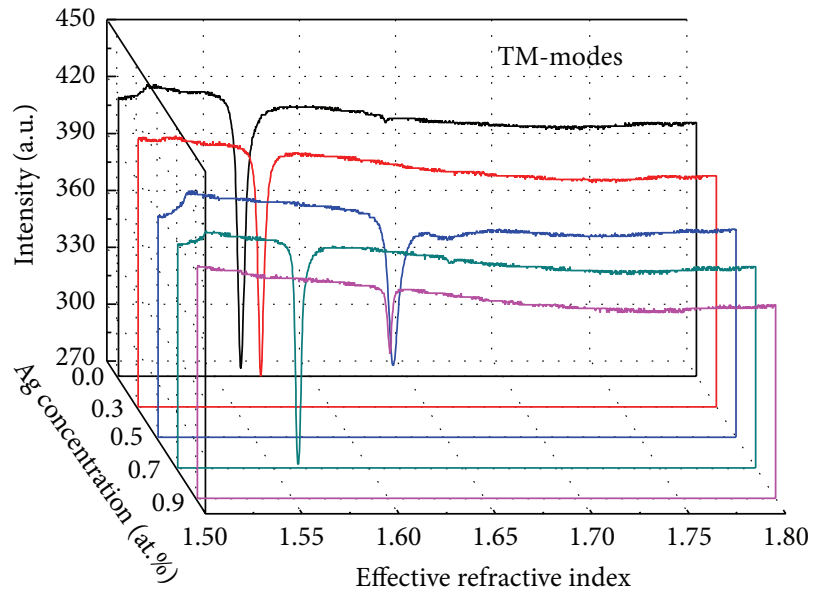

(b)

FIGURE 7: Typical fundamental guided mode spectra of undoped and Ag doped ZnO thin films: (a) TE and (b) TM polarization.

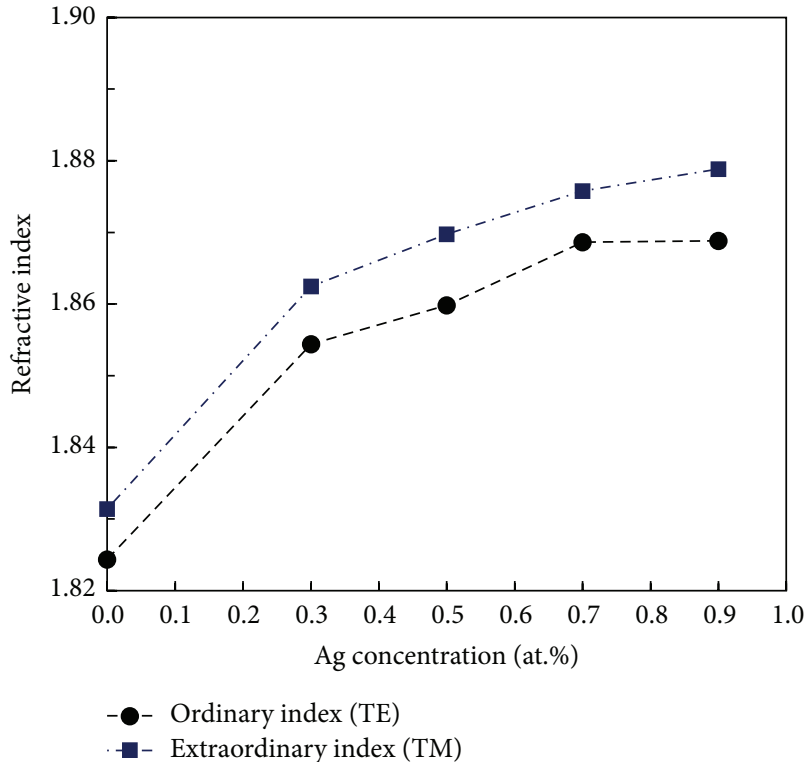

FIGURE 8: Ordinary and extraordinary refractive indexes of undoped and $\mathrm{Ag}$ doped $\mathrm{ZnO}$ thin films.

revealed that all films were in single-phase hexagonal wurtzite structure, highly $c$-axis oriented, and almost stressfree. SEM micrographs and AFM images showed that film morphology and surface roughness were affected by low $\mathrm{Ag}$ doping concentration. All the films were highly transparent with average visible transmission values ranging from $80 \%$ to $86 \%$. The Burstein-Moss effect was observed in all $\mathrm{Ag}$ doped $\mathrm{ZnO}$ thin films. MLS measurements at $632.8 \mathrm{~nm}$ wavelength confirmed that all thin film planar waveguides demonstrated a well-guided single mode for both TE and TM polarization. Furthermore, the refractive index of $\mathrm{ZnO}$ thin films was found to increase by $\mathrm{Ag}$ doping levels. Thus, $\mathrm{ZnO}$ thin films doped with 0.7 and 0.9 at.\% Ag exhibited low surface roughness, highoptical transparency, and better waveguiding properties that possibly will make them suitable for photonic device applications.

\section{Conflict of Interests}

The authors declare that there is no conflict of interests regarding the publication of this paper.

\section{References}

[1] R. E. Marotti, P. Giorgi, G. Machado, and E. A. Dalchiele, "Crystallite size dependence of band gap energy for electrodeposited $\mathrm{ZnO}$ grown at different temperatures," Solar Energy Materials and Solar Cells, vol. 90, no. 15, pp. 2356-2361, 2006.

[2] K. Qiu, Y. Zhao, Y. Gao et al., "Refractive index of a single $\mathrm{ZnO}$ microwire at high temperatures," Applied Physics Letters, vol. 104, no. 8, Article ID 81109, 2014.

[3] W. Liu, K. Wang, H. Long, S. Chu, B. Wang, and P. Lu, "Near-resonant second-order nonlinear susceptibility in c-axis oriented ZnO nanorods," Applied Physics Letters, vol. 105, no. 7, Article ID 071906, 2014.

[4] L. Béaur, T. Bretagnon, B. Gil et al., "Exciton radiative properties in nonpolar homoepitaxial $\mathrm{ZnO} /(\mathrm{Zn}, \mathrm{Mg}) \mathrm{O}$ quantum wells," Physical Review B, vol. 84, no. 16, Article ID 165312, 2011.

[5] K. L. Chopra, S. Major, and D. K. Pandya, "Transparent conductors-a status review," Thin Solid Films, vol. 102, no. 1, pp. 1-46, 1983.

[6] G. M. Nam and M. S. Kwon, "Transparent conducting $\mathrm{Ga}$-doped $\mathrm{ZnO}$ thin film for flat-panel displays with a sol-gel spin coating," Journal of Information Display, vol. 9, no. 3, pp. $8-11,2008$.

[7] S. Major and K. L. Chopra, "Indium-doped zinc oxide films as transparent electrodes for solar cells," Solar Energy Materials, vol. 17, no. 5, pp. 319-327, 1988. 
[8] C.-L. Jia, K.-M. Wang, X.-L. Wang, X.-J. Zhang, and F. Lu, "Formation of c-axis oriented $\mathrm{ZnO}$ optical waveguides by radiofrequency magnetron sputtering," Optics Express, vol. 13, no. 13, pp. 5093-5099, 2005.

[9] W. Peng, Y. He, X. Zhao, H. Liu, X. Kang, and C. Wen, "Study on the performance of $\mathrm{ZnO}$ nanomaterial-based surface acoustic wave ultraviolet detectors," Journal of Micromechanics and Microengineering, vol. 23, no. 12, Article ID 125008, 2013.

[10] M. Zamfirescu, A. Kavokin, B. Gil, G. Malpuech, and M. Kaliteevski, " $\mathrm{ZnO}$ as a material mostly adapted for the realization of room-temperature polariton lasers," Physical Review B: Condensed Matter and Materials Physics, vol. 65, no. 16, Article ID 161205, 2002.

[11] M. Karyaoui, A. Mhamdi, H. Kaouach et al., "Some physical investigations on silver-doped $\mathrm{ZnO}$ sprayed thin films," Materials Science in Semiconductor Processing, vol. 30, pp. 255-262, 2015.

[12] I. S. Kim, E.-K. Jeong, D. Y. Kim, M. Kumar, and S.-Y. Choi, "Investigation of p-type behavior in Ag-doped $\mathrm{ZnO}$ thin films by E-beam evaporation," Applied Surface Science, vol. 255, no. 7, pp. 4011-4014, 2009.

[13] L. N. Wang, L. Z. Hu, H. Q. Zhang et al., "Studying the Raman spectra of $\mathrm{Ag}$ doped $\mathrm{ZnO}$ films grown by PLD," Materials Science in Semiconductor Processing, vol. 14, no. 3-4, pp. 274277, 2011.

[14] T. M. Barnes, J. Leaf, C. Fry, and C. A. Wolden, "Room temperature chemical vapor deposition of c-axis $\mathrm{ZnO}$," Journal of Crystal Growth, vol. 274, no. 3-4, pp. 412-417, 2005.

[15] J.-B. Lee, C.-K. Park, and J.-S. Park, "Physical properties of RF-sputtered $\mathrm{ZnO}$ thin films: effects of two-step deposition," Journal of the Korean Physical Society, vol. 50, no. 4, pp. 10731078, 2007.

[16] M. A. Vasquez-A, O. Goiz, R. Baca-Arroyo, J. A. AndracaAdame, G. Romero-Paredes, and R. Peña-Sierra, "Study of the properties of $\mathrm{ZnO}: \mathrm{Zn}$ thin films obtained from $\mathrm{ZnO} / \mathrm{Zn} / \mathrm{ZnO}$ structure deposited by DC sputtering," Journal of Nanoscience and Nanotechnology, vol. 12, no. 12, pp. 9234-9237, 2012.

[17] J. Xu, Z.-Y. Zhang, Y. Zhang, B.-X. Lin, and Z.-X. Fu, "Effect of Ag doping on optical and electrical properties of $\mathrm{ZnO}$ thin films," Chinese Physics Letters, vol. 22, no. 8, pp. 2031-2034, 2005.

[18] L. Xu, G. Zheng, L. Zhao, and S. Pei, "Two different mechanisms on UV emission enhancement in Ag-doped $\mathrm{ZnO}$ thin films," Journal of Luminescence, vol. 158, pp. 396-400, 2015.

[19] S. W. Shin, I. Y. Kim, K. S. Jeon et al., "Wide band gap characteristic of quaternary and flexible $\mathrm{Mg}$ and $\mathrm{Ga}$ co-doped $\mathrm{ZnO}$ transparent conductive thin films," Journal of Asian Ceramic Societies, vol. 1, no. 3, pp. 262-266, 2013.

[20] K.-C. Kim, E.-K. Kim, and Y.-S. Kim, "Growth and physical properties of sol-gel derived Co doped $\mathrm{ZnO}$ thin film," Superlattices and Microstructures, vol. 42, no. 1-6, pp. 246-250, 2007.

[21] H. Xue, X. L. Xu, Y. Chen, G. H. Zhang, and S. Y. Ma, "Influence of Ag-doping on the optical properties of $\mathrm{ZnO}$ films," Applied Surface Science, vol. 255, no. 5, pp. 1806-1810, 2008.

[22] A. N. Gruzintsev, V. T. Volkov, and E. E. Yakimov, "Photoelectric properties of $\mathrm{ZnO}$ films doped with $\mathrm{Cu}$ and $\mathrm{Ag}$ acceptor impurities," Semiconductors, vol. 37, no. 3, pp. 259-262, 2003.

[23] H. S. Kang, B. D. Ahn, J. H. Kim et al., "Structural, electrical, and optical properties of p-type $\mathrm{ZnO}$ thin films with Ag dopant," Applied Physics Letters, vol. 88, no. 20, Article ID 202108, 2006.
[24] M. Liu, S. W. Qu, W. W. Yu et al., "Photoluminescence and extinction enhancement from $\mathrm{ZnO}$ films embedded with $\mathrm{Ag}$ nanoparticles," Applied Physics Letters, vol. 97, no. 23, Article ID 231906, 2010.

[25] E.-K. Jeong, I. S. Kim, D.-H. Kim, and S.-Y. Choi, "Effect of deposition and annealing temperature on structural, electrical and optical properties of Ag doped $\mathrm{ZnO}$ thin films," Korean Journal of Materials Research, vol. 18, no. 2, pp. 84-91, 2008.

[26] L. Duan, W. Gao, R. Chen, and Z. Fu, "Influence of postannealing conditions on properties of $\mathrm{ZnO}: \mathrm{Ag}$ films," Solid State Communications, vol. 145, no. 9-10, pp. 479-481, 2008.

[27] K. Liu, B. F. Yang, H. Yan et al., "Strong room-temperature ultraviolet emission from nanocrystalline $\mathrm{ZnO}$ and $\mathrm{ZnO}: \mathrm{Ag}$ films grown by ultrasonic spray pyrolysis," Applied Surface Science, vol. 255, no. 5, pp. 2052-2056, 2008.

[28] Y. Chen, X. L. Xu, G. H. Zhang, H. Xue, and S. Y. Ma, "A comparative study of the microstructures and optical properties of $\mathrm{Cu}$-and Ag-doped $\mathrm{ZnO}$ thin films," Physica B: Condensed Matter, vol. 404, no. 20, pp. 3645-3649, 2009.

[29] D. R. Sahu, "Studies on the properties of sputter-deposited Agdoped ZnO films," Microelectronics Journal, vol. 38, no. 12, pp. 1252-1256, 2007.

[30] F. Xian, K. Miao, X. Bai, Y. Ji, F. Chen, and X. Li, "Characteraction of Ag-doped $\mathrm{ZnO}$ thin film synthesized by sol-gel method and its using in thin film solar cells," Optik, vol. 124, no. 21, pp. 4876-4879, 2013.

[31] X. D. Zhou, X. H. Xiao, J. X. Xu, G. X. Cai, F. Ren, and C. Z. Jiang, "Mechanism of the enhancement and quenching of $\mathrm{ZnO}$ photoluminescence by ZnO-Ag coupling," Europhysics Letter, vol. 93, no. 5, Article ID 57009, 2011.

[32] S. Khodja, T. Touam, A. Chelouche et al., "Effects of stabilizer ratio on structural, morphological, optical and waveguide properties of $\mathrm{ZnO}$ nano-structured thin films by a sol-gel process," Superlattices and Microstructures, vol. 75, pp. 485-495, 2014.

[33] M. K. Puchert, P. Y. Timbrell, and R. N. Lamb, "Postdeposition annealing of radio frequency magnetron sputtered $\mathrm{ZnO}$ films," Journal of Vacuum Science and Technology A: Vacuum, Surfaces and Films, vol. 14, no. 4, pp. 2220-2230, 1996.

[34] M. Chen, Z. L. Pei, C. Sun, L. S. Wen, and X. Wang, "Surface characterization of transparent conductive oxide Al-doped ZnO films," Journal of Crystal Growth, vol. 220, no. 3, pp. 254$262,2000$.

[35] J. I. Langford and A. J. C. Wilson, "Scherrer after sixty years: a survey and some new results in the determination of crystallite size," Journal of Applied Crystallography, vol. 11, no. 2, pp. 102113, 1978.

[36] S.-T. Kuo, W.-H. Tuan, J. Shieh, and S.-F. Wang, "Effect of Ag on the microstructure and electrical properties of $\mathrm{ZnO}$," Journal of the European Ceramic Society, vol. 27, no. 16, pp. 4521-4527, 2007.

[37] A. Sanchez-Juarez, A. Tiburcio-Silver, A. Ortiz, E. P. Zironi, and J. Rickards, "Electrical and optical properties of fluorine-doped $\mathrm{ZnO}$ thin films prepared by spray pyrolysis," Thin Solid Films, vol. 333, no. 1-2, pp. 196-202, 1998.

[38] N. Volbers, H. Zhou, C. Knies et al., "Synthesis and characterization of $\mathrm{ZnO}: \mathrm{Co}^{2+}$ nanoparticles," Applied Physics A: Materials Science and Processing, vol. 88, no. 1, pp. 153-155, 2007.

[39] L. Li, W. Wang, H. Liu, X. Liu, Q. Song, and S. Ren, "First principles calculations of electronic band structure and optical properties of Cr-doped $\mathrm{ZnO}$," The Journal of Physical Chemistry C, vol. 113, no. 19, pp. 8460-8464, 2009. 
[40] D. Nečas and P. Klapetek, "Gwyddion: an open-source software for SPM data analysis," Central European Journal of Physics, vol. 10, no. 1, pp. 181-188, 2012.

[41] M. Wang, E. J. Kim, S. Kim et al., "Optical and structural properties of sol-gel prepared $\mathrm{MgZnO}$ alloy thin films," Thin Solid Films, vol. 516, no. 6, pp. 1124-1129, 2008.

[42] M.-C. Jun and J.-H. Koh, "Effects of NIR annealing on the characteristics of al-doped $\mathrm{ZnO}$ thin films prepared by $\mathrm{RF}$ sputtering," Nanoscale Research Letters, vol. 7, article 294, 2012.

[43] S. H. Jeong, B. N. Park, S.-B. Lee, and J.-H. Boo, "Metal-doped ZnO thin films: synthesis and characterizations," Surface and Coatings Technology, vol. 201, no. 9-11, pp. 5318-5322, 2007.

[44] E. Burstein, "Anomalous optical absorption limit in InSb," Physical Review, vol. 93, no. 3, pp. 632-633, 1954.

[45] T. S. Moss, "The interpretation of the properties of indium antimonide," Proceedings of the Physical Society. Section B, vol. 67, no. 10, article 775, 1954.

[46] P. K. Tien and R. Ulrich, "Theory of prism-film coupler and thin-film light guides," Journal of the Optical Society of America, vol. 60, no. 10, pp. 1325-1337, 1970.

[47] W. L. Bond, "Measurement of the refractive indices of several crystals," Journal of Applied Physics, vol. 36, no. 5, pp. 1674-1677, 1965.

[48] M. García-Alamo, O. Rodriguez-Nava, A.-J. Morales-Ramírez, M. García-Hernández, and D. Jaramillo-Vigueras, "Synthesis and antibacterial properties of $\mathrm{ZnO}$ :Ag films prepared from a Triton containing solution," Materials, vol. 6, pp. 1-10, 2013. 

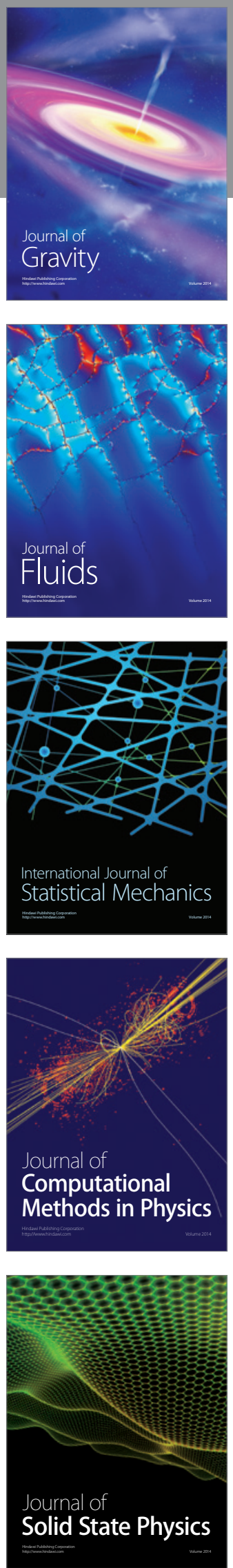

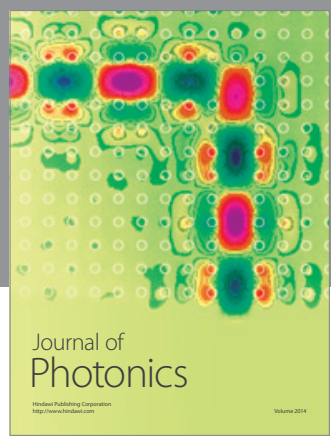

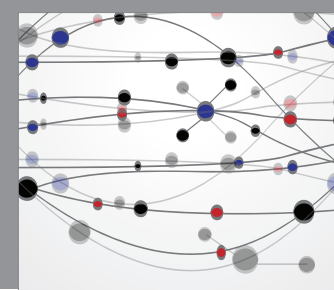

The Scientific World Journal

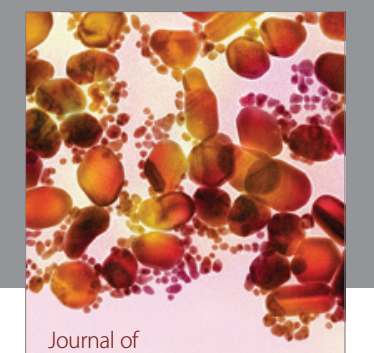

Soft Matter
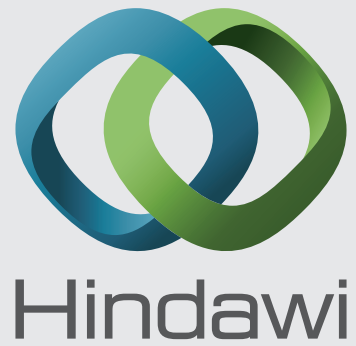

Submit your manuscripts at

http://www.hindawi.com
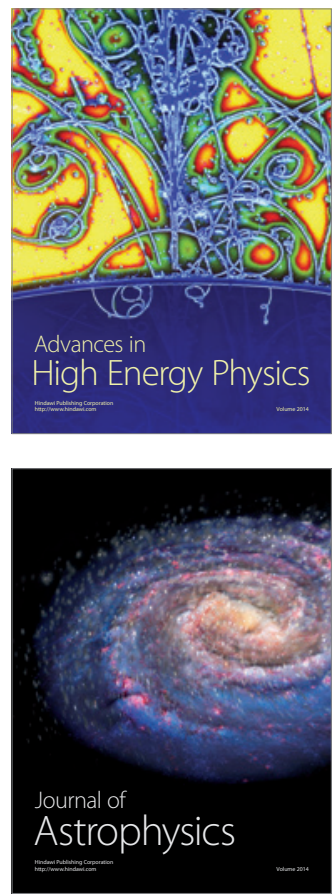
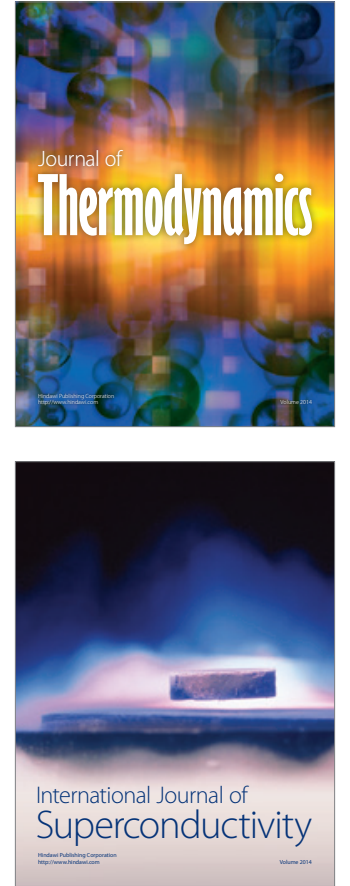
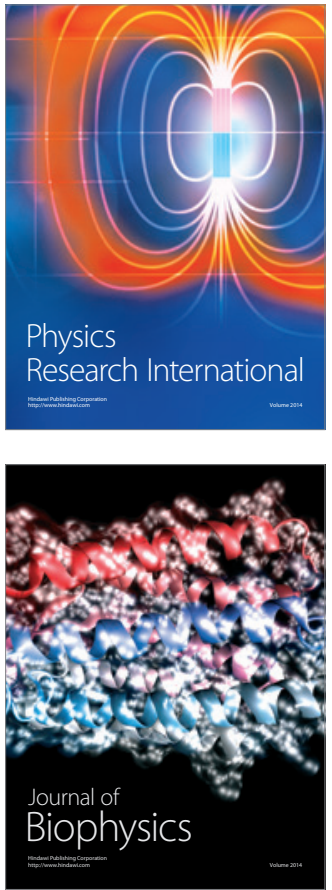
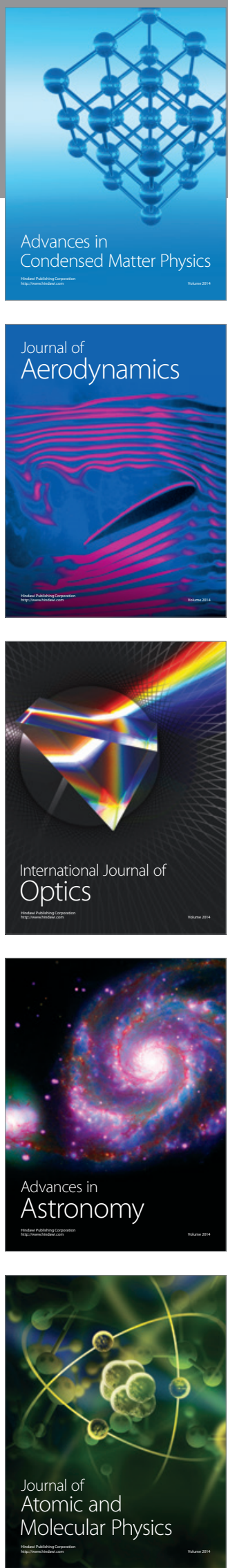